\title{
Overview of Analyses of Purified Pharmaceutical water through Proficiency-testing Schemes Results
}

\section{Caterina Mazzoni*, Anne Tirard and Abdelkader Boubetra}

BIPEA (Bureau Interprofessionnel des Etudes Analytiques), Scientific and Technical Department, 189 rue d'Aubervilliers, Paris, France *Corresponding Author: Caterina Mazzoni, BIPEA (Bureau Interprofessionnel des Etudes Analytiques), Scientific and Technical Department, 189 rue d'Aubervilliers, Paris, France.

Received: September 20, 2021; Published: October 01, 2021

\begin{abstract}
Water is one of the major components used by the pharmaceutical industry. It may be present as an excipient or used for reconstitution of products, during synthesis, during production of the finished product or as a cleaning agent. Different grades of water quality are required depending on the different pharmaceutical uses. Chemical, physical and microbiological quality controls are essential to verify that the produced water meets the regulations in force. The methods that must be applied for quality control of water for pharmaceutical purpose are described in the international Pharmacopeia. However, laboratories have few means at their disposal to check obtained results and to prove their competence to drug regulatory agencies and customers associations. As Certified Reference Materials (CRM), Proficiency Testing Schemes (PTS) is an excellent tool to objectively check laboratories performances. Moreover, data collected in PTS represent a snapshot of the state of the art of tested analytical methods. Keywords: Proficiency-testing schemes; Purified pharmaceutical water; Endotoxins, IN total organic carbon; Total viable aerobic germs; Quality control; Laboratory performance
\end{abstract}

\section{Introduction}

Chemical, physical and microbiology analyses can be carried out during commercial transactions to ensure the conformity of the goods, during the quality control to verify that the products meet the regulations in force or correspond to the specifications.

The quality of the analyses results must be guaranteed by the laboratories, an erroneous result can have serious consequences on the economic or health plan. Laboratories have various analysis methods available, which standardization is more or less advanced, this state of progress depending essentially on the needs (existence of regulations or trade).

Pharmaceutical companies are invited to follow the analysis methods described in the international Pharmacopeia. However, even if the laboratory carries out routine analyses following a defined method, these analyses can be subject to various types of errors, both random and systematic. The most important errors can be easily identified by operators if they lead to results that are out of specifications (OOS) of the product being analysed. In order to detect other errors and to guarantee the quality of its analytical results, the laboratory has at its disposal various means of monitoring, such as Certified Reference Materials (CRM) which are often used in pharmaceutical quality check. However, CRM are expensive and laboratories can't compare their results each other on the same sample. One of the most effective method of monitoring the laboratory performances is the participation to Proficiency Testing Schemes (PTS). Widely used in the agri-food and environmental sectors, this type of testing is increasingly catching on in the pharmaceutical sector.

Water plays a central role in pharmaceutical production. Water is used as an excipient, for reconstitution, during the synthesis or production of finished products and for the cleaning and rinsing of containers, equipment and primary packaging materials in the pharmaceutical industry. Pharmaceutical water meets high quality requirements, both as a product component and for production 
purposes. Quality control of water is a major concern and the pharmaceutical industry devotes considerable resource to the development and maintenance of water purification systems.

Chemical, physical and microbiological quality controls are essential for a production compliant with the requirements of Good Manufacturing Practice (GMP) and are prescribed by current legislations.

The European Pharmacopoeia [1] provides quality standards for grades of water for pharmaceutical use including purified water (Aqua purificata), in a bulk or packaged form, highly purified water (Aqua valdepurificata) and water for injections (Aqua ad iniectabilia) in a bulk or sterilized form [2]. The quality standards for these products are the same in terms of total organic carbon (TOC) and endotoxins content, as they should contain less than $0.5 \mathrm{mg} / \mathrm{L}$ of TOC and less than $0.25 \mathrm{IU} / \mathrm{mL}$ of bacterial endotoxins. Concerning microbiological analyses, the number of colonyforming units per $\mathrm{mL}(\mathrm{CFU} / \mathrm{mL}$ ) must be less than 100 for purified water and 10 for highly purified water and water for injections.

Few PTS are available for quality control in the pharmaceutical field even if an untrue analytical result can have significant consequences both from an economic and a public health point of view. PTS are interesting not only for laboratories, who can compare the results each other and have a confirmation that they obtaintrue results, but also to gain instant feedback on laboratories performances in analysed matrices related to current regulations.

Regular proficiency-testing schemes on purified pharmaceutical water have been organized by BIPEA since June 2020 according to ISO 17043 standard [3]. The aim of this study is to analyse results obtained in recent PTS for endotoxins, TOC and total viable aerobic germs quantification in purified water.

\section{Materials and Methods}

Nine different samples of purified water were prepared and sent to the participants for three different PT within one year.

For each test, three types of batches were prepared:

- $\quad$ Samples of purified water spiked with endotoxins.

- Samples of purified water spiked with organic carbon.

- Samples of purified water spiked with microorganisms for total viable aerobic germs quantification.

\section{Preparation of the samples spiked with endotoxins}

High purified water was homogenized and divided into samples of $200 \mathrm{~mL}$ using suitable equipment. These samples were individually spiked by adding a calibrated solution of endotoxins in water. The theoretical targets of endotoxin concentration in the samples are summarized in Table 1.

Preparation of the samples spiked with organic carbon

A batch of $6 \mathrm{~L}$ of hight purified water was spiked with sucrose at a well-defined concentration. After homogenisation, the batch was divided into samples of $200 \mathrm{~mL}$. The TOC spiking concentrations of prepared batches are listed in Table 2.

Preparation of the samples for microbiological analyses

Samples were prepared by spiking a batch of purified water with suspensions of Bacillus cereus in well controlled proportions to reach concentrations between 10 to $40 \mathrm{CFU} / \mathrm{mL}$. 


\section{Homogeneity and stability check}

Homogeneity and stability checks were performed on all produced batches according to the requirements of ANNEX B of the ISO 13528 standard [4] to ensure that the samples were as identical as possible to each other to avoid interpreting the deviations related to the samples as accuracy errors of the laboratories.

\section{Results collection and data statistical treatment}

Prepared the samples were shipped at $5 \pm 3^{\circ} \mathrm{C}$ to all participants, who are invited to analyse the samples as soon as possible after reception.

The results of laboratories are collected via a reply form available online over a period of 4 weeks.

The statistical treatments of the returned results are conducted according to ISO 13528 [4]. The assigned values ( $\mathrm{x}_{\mathrm{pt}}$ ) are estimated using the robust means of all results from the application of robust algorithm A. Laboratories with a lack of traceability are not taken into account in the statistical estimations.

Performances of each laboratory are evaluated using robust standard deviations ( $\mathrm{s}^{*}$ ) set as the standard deviation for performance assessment $\left(\sigma_{p t}\right)$. This value is used to identify an interval around the assigned value. Results in this range are considered as satisfactory.

Moreover, laboratory results ( $\mathrm{x}$ ) are also evaluated through z-scores $(\mathrm{z})$. The z-score for a result xi is calculated as:

$$
\mathrm{Z}_{\mathrm{i}}=\frac{(x \mathrm{i}-x \mathrm{pt})}{\sigma \mathrm{pt}}
$$

Where $\sigma_{p t}$ is the standard deviation for proficiency assessment. Laboratories with a " $\mathrm{z}$ score $\leq|2|$ " or "z score $>|3|$ " are considered having reported "Satisfactory" or "Unsatisfactory" results, while results of laboratories having z-score between this interval (" $|2|<$ z-score < $|3|$ ") are judged as "Questionable".

\section{Results and Discussions}

Main statistical parameters of these Proficiency Tests (PT) are described in Table 1. Even if 25 laboratories subscribed their participation in at least one PT out of the nine proposed, only few laboratories returned quantifiable results. However, assigned values could be evaluated for all proposed parameters. Uncertainties, $u\left(x_{p t}\right)$, that allow quantification of the confidence that can be given to the assigned value, were calculated as indicated in paragraph 7.7 of the ISO 13528 standard [4]. Very few untrue results were observed in these PT.

Dispersion of the results, provided as coefficient of variation (CV, robust standard deviation of the results / robust mean of the results, in \%), differs from a parameter to another. Globally, results obtained for TOC are the least dispersed. However, for this analytical parameter, laboratories returned results higher than the theoretical values (spiking values), with recovery rates greater than $100 \%$. All participants applied the method described in the European Pharmacopeia.

Laboratories results for endotoxin analyses show the lowest recovery rates and are quite dispersed. Different analytical methods were used by participants: most of laboratories (81\% of participants) follow one out of the 6 methods described in the European Pharmacopeia (Gel-clot: limit test, Gel-clot: semi quantitative test, Turbidimetric kinetic, Chromogenic kinetic, Chromogenic end-point and Turbidimetric end-point methods) [1]. Table 2 details the methods announced by participants for the 3 PT organized for endotoxins. In this table, laboratories z-scores are shown too. No tendencies as a function of the applied method can be highlighted. However, the 
different methods used by participants could be the cause of results dispersion. Recovery rates is an aspect that deserves to be monitored, as remains low for endotoxins, especially for the first (47\%) and third PT (55\%).

Results obtained for total viable aerobic germs quantification are satisfactory, as no laboratory found untrue results. Recovery rates are good for a spiking rate of around $30 \mathrm{CFU} / \mathrm{mL}$, but decrease at lower spiking concentration (closer to the $10 \mathrm{CFU} / \mathrm{mL}$ that corresponds to the target limit for highly purified water and water for injections). All laboratories follow the European Pharmacopeia method. For this analysis, most of participants used R2A as growth medium.

\begin{tabular}{|c|c|c|c|c|c|c|c|c|c|c|}
\hline \multicolumn{11}{|c|}{ Endotoxins } \\
\hline PT & $\begin{array}{c}\mathrm{x}_{\mathrm{pt}}{ }^{1} \\
\mathrm{IU} / \mathrm{mL}\end{array}$ & $\begin{array}{l}\mathrm{u}\left(\mathrm{x}_{\mathrm{pt}}\right)^{2} \\
\mathrm{IU} / \mathrm{mL}\end{array}$ & $\begin{array}{l}\mathrm{s}\left(\mathrm{x}_{\mathrm{pt}}\right)^{3} \\
\mathrm{IU} / \mathrm{mL}\end{array}$ & $\mathrm{p}\left(\mathrm{x}_{\mathrm{pt}}\right)^{4}$ & $\begin{array}{c}\mathrm{CV}\left(\mathrm{x}_{\mathrm{pt}}\right)^{5} \\
\%\end{array}$ & $\begin{array}{l}2^{*} \sigma_{\mathrm{pt}}{ }^{6} \\
\mathrm{IU} / \mathrm{mL}\end{array}$ & $\mathrm{p}_{\mathrm{u}}{ }^{7}$ & $\mathrm{p}_{\mathrm{CA}}{ }^{8}$ & $\begin{array}{c}\mathrm{x}_{\mathrm{SP}}{ }^{9} \\
\mathrm{IU} / \mathrm{mL}\end{array}$ & $\begin{array}{c}\mathrm{RR}^{10} \\
\%\end{array}$ \\
\hline 1 & 0.47 & 0.10 & 0.17 & 5 & 36 & 0.34 & 1 & 7 & 1.00 & 47 \\
\hline 2 & 0.93 & 0.16 & 0.25 & 4 & 27 & 0.50 & 1 & 6 & 1.33 & 70 \\
\hline 3 & 0.44 & 0.07 & 0.13 & 5 & 30 & 0.26 & 0 & 7 & 0.80 & 55 \\
\hline \multicolumn{11}{|c|}{ TOC } \\
\hline PT & $\begin{array}{l}\mathrm{x}_{\mathrm{pt}}{ }^{1} \\
\mathrm{ppm}\end{array}$ & $\begin{array}{c}\mathrm{u}\left(\mathrm{x}_{\mathrm{pt}}\right)^{2} \\
\mathrm{ppm}\end{array}$ & $\begin{array}{l}\mathrm{s}\left(\mathrm{x}_{\mathrm{pt}}\right)^{3} \\
\mathrm{ppm}\end{array}$ & $\mathrm{p}\left(\mathrm{x}_{\mathrm{pt}}\right)^{4}$ & $\begin{array}{c}\mathrm{CV}\left(\mathrm{x}_{\mathrm{pt}}\right)^{5} \\
\%\end{array}$ & $\begin{array}{c}2^{*} \sigma_{\mathrm{pt}}{ }^{6} \\
\mathrm{ppm}\end{array}$ & $\mathrm{p}_{\mathrm{u}}{ }^{7}$ & $\mathrm{p}_{\mathrm{CA}}{ }^{8}$ & $\begin{array}{l}\mathrm{x}_{\mathrm{SP}}{ }^{9} \\
\mathrm{ppm}\end{array}$ & $\begin{array}{c}\mathrm{RR}^{10} \\
\%\end{array}$ \\
\hline 4 & 0.8 & 0.0 & 0.0 & 4 & 0 & 0.1 & 0 & 4 & 0.7 & 119 \\
\hline 5 & 1.2 & 0.1 & 0.2 & 5 & 17 & 0.4 & 1 & 7 & 1.1 & 109 \\
\hline 6 & 0.7 & 0.1 & 0.1 & 6 & 14 & 0.2 & 1 & 8 & 0.6 & 125 \\
\hline \multicolumn{11}{|c|}{ Total viable aerobic germs } \\
\hline PT & $\begin{array}{c}\mathrm{x}_{\mathrm{pt}}{ }^{1} \\
\mathrm{CFU} / \mathrm{mL}\end{array}$ & $\begin{array}{c}\mathrm{u}\left(\mathrm{x}_{\mathrm{pt}}\right)^{2} \\
\mathrm{CFU} / \mathrm{mL}\end{array}$ & $\begin{array}{l}\mathrm{s}\left(\mathrm{x}_{\mathrm{pt}}\right)^{3} \\
\mathrm{CFU} / \mathrm{mL}\end{array}$ & $\mathrm{p}\left(\mathrm{x}_{\mathrm{pt}}\right)^{4}$ & $\begin{array}{c}\mathrm{CV}\left(\mathrm{x}_{\mathrm{pt}}\right)^{5} \\
\%\end{array}$ & $\begin{array}{c}2 * \sigma_{\mathrm{pt}}{ }^{6} \\
\mathrm{CFU} / \mathrm{mL}\end{array}$ & $\mathrm{p}_{\mathrm{u}}{ }^{7}$ & $\mathrm{p}_{\mathrm{CA}}{ }^{8}$ & $\begin{array}{c}\mathrm{x}_{\mathrm{SP}}{ }^{9} \\
\mathrm{CFU} / \mathrm{mL}\end{array}$ & $\begin{array}{c}\mathrm{RR}^{10} \\
\%\end{array}$ \\
\hline 7 & 31 & 3 & 6 & 6 & 19 & 12 & 0 & 8 & 35 & 89 \\
\hline 8 & 28 & 4 & 8 & 7 & 29 & 16 & 0 & 9 & 31 & 90 \\
\hline 9 & 14 & 1 & 1 & 6 & 7 & 2 & 0 & 7 & 29 & 48 \\
\hline
\end{tabular}

1. $x_{\mathrm{pt}}$ : Assigned value

2. $\mathbf{u}\left(\mathbf{x}_{\mathrm{pt}}\right)$ : Standard uncertainty of the assigned value: $u\left(x_{\mathrm{pt}}\right)=1.25 * s^{*} / \sqrt{\mathrm{p}(\mathrm{xpt})}$

3. $s\left(x_{p}\right)$ : Robust standard deviation of the results

4. $\boldsymbol{p}\left(\boldsymbol{x}_{p}\right)$ : Number of results taken into account for the estimation of the assigned value

5. $\boldsymbol{C V}\left(\boldsymbol{x}_{p}\right)$ : Coefficient of variation

6. $\sigma_{\mathrm{pt}}:$ Twice the standard deviation for proficiency assessment (tolerance value)

7. $\boldsymbol{p}_{u}:$ Number of unsatisfactory results

8. $\boldsymbol{P}_{C A}$ : Participants

9. $\boldsymbol{X}_{s p}:$ Spiking value

10. $\boldsymbol{R}$ : Recovery rate: $100-\left(\left(\mathrm{x}_{\mathrm{PT}}-\mathrm{x}_{\mathrm{SP}}\right) / \mathrm{x}_{\mathrm{SP}}{ }^{*} 100\right)$.

Table 1: Summary of the statistical treatment of the data of Proficiency Testson purified water: endotoxins, TOC and total viable aerobic germs content. 
Overview of Analyses of Purified Pharmaceutical water through Proficiency-testing Schemes Results

\begin{tabular}{|c|c|c|c|}
\hline Test & Laboratory & Method performed for Endotoxin detection & $\mathrm{z}$-score \\
\hline \multirow{7}{*}{1} & $1 \mathbf{a}$ & European pharmacopeia - Chromogenic & -0.53 \\
\hline & $2 \mathbf{a}$ & European pharmacopeia - Chromogenic kinetic & -0.94 \\
\hline & $\mathbf{3 a}$ & European pharmacopeia - Turbidimetric & 2.53 \\
\hline & $4 a$ & European pharmacopeia - Turbidimetric & -0.47 \\
\hline & $5 \mathbf{a}$ & European pharmacopeia - Not specified & 0.29 \\
\hline & $6 a$ & European pharmacopeia - Not specified & -0.18 \\
\hline & $7 \mathbf{a}$ & Alternative method- in-house method based on pharmacopeia Gel-Clot & 1.41 \\
\hline \multirow{6}{*}{2} & $1 \mathbf{b}$ & European pharmacopeia - Endosafe - Charles River & -1.28 \\
\hline & $2 \mathbf{b}$ & European pharmacopeia - Chromogenic & 0.76 \\
\hline & $\mathbf{3 b}$ & European pharmacopeia - Chromogenic & 0.32 \\
\hline & $4 \mathbf{b}$ & European pharmacopeia - Gel-Clot & 0.12 \\
\hline & $\mathbf{5 b}$ & European pharmacopeia - Not specified & 4.44 \\
\hline & $6 \mathbf{b}$ & Alternative method - Chromogenic kinetic method & -1.84 \\
\hline \multirow{8}{*}{3} & $1 c$ & European pharmacopeia - Endosafe - Charles River & -1.31 \\
\hline & $2 c$ & European pharmacopeia - Chromogenic & 1.00 \\
\hline & $3 c$ & European pharmacopeia - Chromogenic kinetic method & 1.54 \\
\hline & $4 c$ & European pharmacopeia - Chromogenic kinetic method & 1.54 \\
\hline & $5 c$ & US pharmacopeia - Chromogenic & 0.15 \\
\hline & 6c & European pharmacopeia - Gel-Clot & 0.31 \\
\hline & 7c & European pharmacopeia - Not specified & -0.23 \\
\hline & 8c & Other method - LAL assay & 0.46 \\
\hline
\end{tabular}

Table 2: Proficiency Tests "Endotoxins on purified water": laboratories performances (as z-score) as a function of the applied method.

\section{Conclusions}

Despite a number of results that remains limited, the study of the results of these proficiency tests provides valuable information about the current state of art on the quality control of purified water. Results are satisfactory, even if some discrepancies are observed between spiking concentrations and robust means of the results returned by participants in these PT. Data obtained on analyses of endotoxins are less satisfying than those of TOC and total viable aerobic germs analyses, as the results are more dispersed and recovery rates lower.

In general, it may happen that, when PTS are launched in a new field (matrix and/or analyte), laboratories results are quite dispersed. Participants need to assess their data and implement corrective and curative actions, if necessary, to improve their performances.

The main objective of the development of a dedicated proficiency testing scheme on purified pharmaceutical water is to allow the participants laboratories to compare with each other, draw up a general inventory of their analytical skills, improve their performances and, above all, meet the requirements of GMP (good manufacturing practice) and gain trust of customers associations.

\section{Acknowledgements}

BIPEA acknowledges all laboratories participating in these PTS. 


\section{References}

1. Guideline on the quality of water for pharmaceutical use. European Medicines Agency (2018).

2. European Pharmacopoeia $10^{\text {th }}$ Edition, Paragraph 2.6.14: Bacterial Endotoxins.

3. ISO/IEC 17043:2010 - Conformity assessment -General requirements for proficiency testing.

4. ISO/IEC 13528:2015, Statistical methods for use in proficiency testing by interlaboratory comparisons.

\section{Volume 1 Issue 2 October 2021}

(C) All rights are reserved by Caterina Mazzoni., et al. 